\title{
關於中國科學院的基本情况 和今後工作任務的報告
}

(1954 年1月28日郭沫若院長在政務院第 204 次政務會耧上 的報告，並經同次會議批准）

中華人民共和國成立以來，中國的科學䂰究工作，在中央人民政府的領導下，䌊過

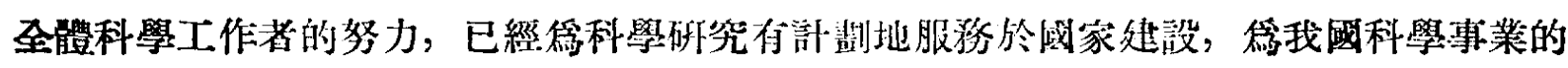
淮一步發屡創造了一定的條件。對於中國科學院來筧，今天也已經有可能從現有基礎上 出弡，根據國家在過渡時期的總路綫和治任務的要求，提州今後工作的方針和任務。

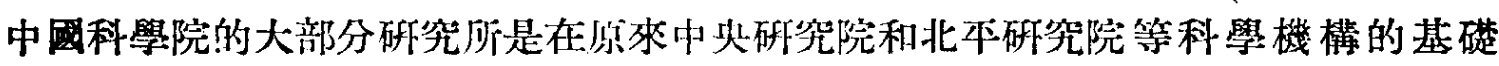
上起立起來的。1952 年以前，科學院主要進行了團結科學家和謌整機構的工作，使過去 機棈重悬、人力分散和思想混魜的情况，得到了改善。195̣2 年接受了東北人民政府工業 部所移交的東北科學碑究所及其大連分所，並合问從上海、北京遷往東北的其他研究機 構，組成東北分院，加强了科學院技術科學方面的力量。隨着革命事業在各個方面的腧 利，特別是各種的會改革運動和抗美援朝的勝利，随着工莀業生產的恢復和發展，我國 的科學事業问樣也起了根本的變化。過去被反動的國民黨政權㗜作裝飾品的科學研究機 構，已經轉督雼人民事業的一部分了。絕大多數的科學家都已經參加了“鎮反”、“三反”、

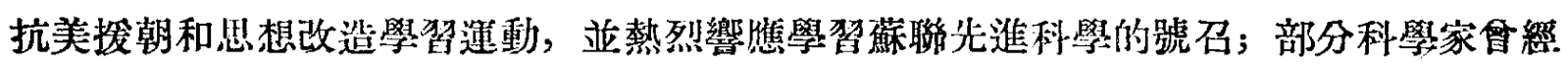

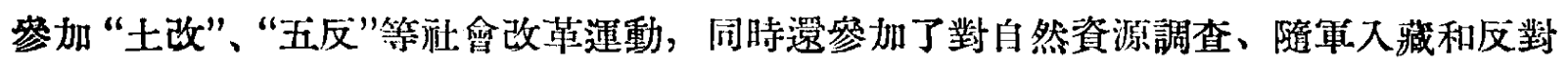
細菌戰等工作，因而大大地提高了他們的政治覺悟。在科學研究工作本身，也完成了一 些有價值的科學研究題目。

1953 年 9 月底的統計，科學院共有 36 個科學研究機構 (25 個研究所， 4 個獨立的 研究室, 4 個研究所的籌備處和天文台、儀器館、菌種保藏委員會), 其中 15 個在北京, 13 個在華東，8個在東北。全院共有 1,725 個專業的科學研究人員，其中副研究員以上 的高級研究人員 347 人。四年中，在科學研究方面主要有下面一些成綪: (一)在國家白 然條件調查與資源勘察方面: 配合地質部進行了大規模的地質調査與勘探工作，援大了 某些磺區，提高了磺藏的估計儲量，如內蒙、大治的鐵磺，東北、西北的煤礦，甘楅的 有色金屬磺等都有新的現; 與隶象局合作改進了短期天氣預報、提漓了準確度，並開 始中期天氮預報，對國防、農田水利起了相當大的作用; 又會同農、林等部門進行了植 物、土壤與魚類的調查。（二)在配合工農業生產方面: 球墨鎈鐡的試製成功，在機械工 業上提供了成本低、性能好的新的金屬材料; 人造橡膠的合成已有結果，現在繼縝研究 
改進其品質；甲苯的提煉與試慗的成功，有利於解決國防工業重要原料生产的問題; 紙 嶈及各種特效葲物的試慗等，對有關的工業生產都有一定的作用; 除草防蚜的辦法，已

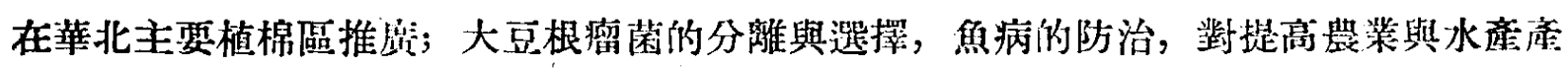
量方面都有所面獻。(三)在自然科學基本理論研究方面: 物理學的研究上, 在原子核:汤 理方面及其他方面進行了一些工作; 數學的研究上, 修訂出版了堆嘼素政諭; 化學的研究

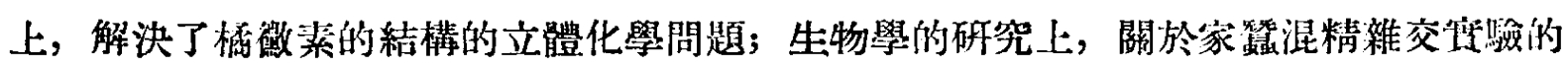
結果給米邱林遺傅學說提供了新的論證。(四)社會科學方面: 在歷史、語言的研究中, 在經沿資料的搜集整理和考古發掘中，都有一定的成績。此外，1951 年随着西藏的和本

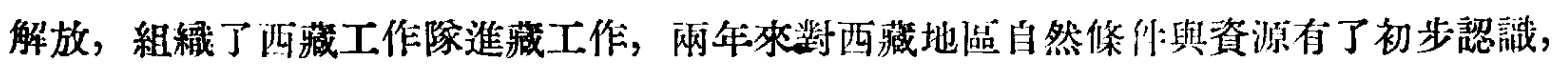

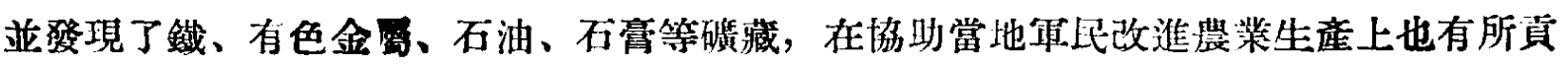
獻。在反細菌戰鬥争中，院內外的科學工作者都管經起了積極作朋。

上述工作成就與當前國家需要相比, 㙷然足很不够的。面中或科學水本不高, 加以 科學院工作中向存在着許多缺點, 科學院現有的潛在力量也䢱沒有能充分發揮出桃。

目前科學院存在的問題主要的有下列幾個方面:

(一)進一步瞭解中國現有科學基礎利力量的問題。舊中國的科學基礎薄弱, 展不 本衡，人數甚少，解放後四年来的發展，仍遠落後於國家建設们要求。就科學院本身

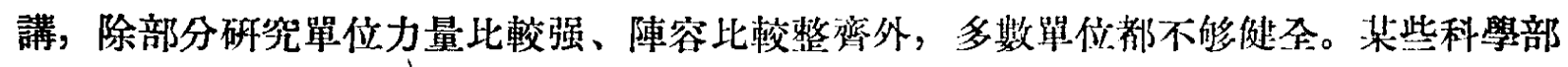
門中的一些重要環節, 或則力量很弱或則全無基礎。例如植物學方面, 哳栄植物生態學 和地植物學的人極少; 動物學方面沒有研究哺乳動物的專家; 選傳學和微生物學方面 的基礎都很善。化學方面, 與重工業密切關聯的無機化學、分析化學力量很弱。地球物 理學方面, 關於地震的專家極少, 遠不能適雔當前基本建設的需要。技術科學方面, 除 冾金陶登研究所有一定基礎外，其餘都是在東北工業恢復時期中才新建立起來的。因此， 就我國科學水本看, 科學院是集中了一批水本较高的科學人材, 但按當前惐家处钤任務 的要求來說, 我㑚今天的基礎和力量顯然是不能癷任的。院外的科學呼究力量, 各分作 在各產業部門與高等學校中，彼此缺乏經常的聯系，因而也就未能充分地合理使用。䍃 了在現有基礎上適常地組織科學研究的力量, 使之能最有效地在國家趎設中發捚作用, 首先就需要加强調查研究, 進一步全面地瞭解我國現有科學㠿礎利力量, 立㑕以製訂碓 實可行的工作計劃與發展計劃，這是目前科學院工作中首要的也是最梏本们問題。

（二)培養科學幹部與加强團結科學家的工作問題。積極培養科·學翰部是科學發展的

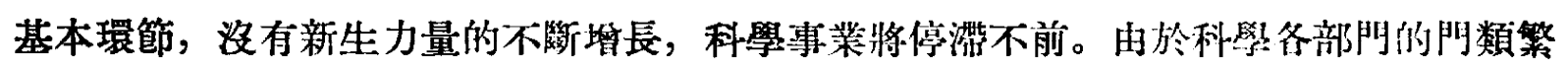
多, 要求各異, 要培養出具有獨立研究能力的科學幹部絕非一朝一夕所能奏效。科學院 對培養科學幹部的工作, 過去缺少認㱏的計劃, 只停留在一般號召上, 沒有一定的制度 和程常的領導。除少數研究單位領導上比較重視, 收到一定的成績外, 一般都做得很 差, 没有積累多少經驗。因此, 必須在全院範園內使大家從思想上明礁培養幹部是科學

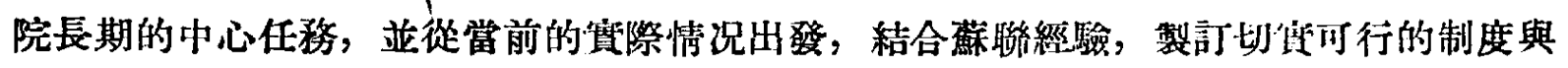
辩法。與此同時, 必須加强團䊅科學家的工作，只有發揮現有科學家的皘極性，不斷提 
高他郡的科學水本與思想水本，才能做好研究工作和培養年輕一代的工作。目前有不少 的老科學家對培養幹部的工作很重視，靑年人也能虚心向老科學家學習。但也有些等年 人與老科學家之間還存在着某些不協調現像。青年人往往對老科學家要求過㬏、過急， 或者是片面强調科學的實際隹用價值和個人發展前途。因此必須教育青年尊重老科學 家，並認地向老科學家學習，使他㑡在科學砋究業務上發揮高度的積極性和㓱造性， 並願意把自己的知識和經驗傳授給下一代。必須給老科學家以一定的生活和工作條件， 對於他㑡的發明和創造必須給以物質或精神獎謜，拿重他㑡的知識勞䡃的成果。今後必 須加强對各研究所的思想工作，使團結科學家的工作和科學幹部的培養工作，能够統一 地、正確地予以實現。

（三）關於具體貫徽理論結合實際方針問題。理諭必須與實際結合，科學要鸽四傢建

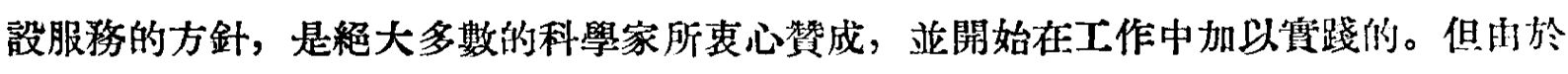
科學院對於如何具體貫徹理論結合货際的方針，缺少認真的研究和進行必要啲工作，過 去對國家的經濟計劃䐲解很少, 對產業部門聯系做得也很不够, 因此各研究所在具體執

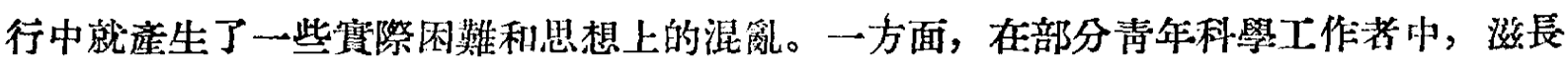
着把理諭聯系實際簡單化的傾向，他們往往把“偭際”理解售純粹的直接的生產任務。另 一方面，也有一些人脫離了實際情况，片面强調科學院研究所必須研究高哚理渝問題， 甚至認䍃解決目前生座上的問題不能算足科學工作。這主要是思想認識上的不明確、不 一致, 以及不能從研究所的具體情况出發，一般地提問題的結果。今後必須結合製訂政 究計劃的工作，具體地規定各所的研究方向和業務重點，來貫徹理論結合寒際的方針。 问時, 科學院今後隹加强與産業部門的聯系, 促進科學研究興生建設的垥造性合作, 逗是解决理論聯系實際問題的一個重要環節。

(四) 關於組織領導方面的問題。科學院是學術研究機構，它和一般機關在性質上有 所不问。因此科學院在組緎機構上、在領導方法上就必須從科學院的特點出發，做到能 够证確地、有效地領導全國科學活動，首先是領導好本院所屬各䃟究所的科學研究工作。 目前科學院的領導機構和領導方法與政府其他部門沒有多大的區别。首先，未能邀當地 組織國內優秀的科學家參加學術領導工作，而這對於加强科學院的學術領導，使科學院 成鸽名符其貫的全國科學研究的中心是具有決定意義的問題。在領導方法上未能抓住科 學業務的特點，工作一般化。科學院各項工作必須图絔科學紧務進行，這一點也是最近 才明確起來。一些必要的學術活動如召開科學會議、組織學術討論, 解決生新和學迶上

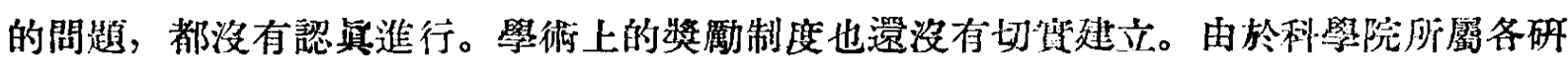
究單位散處各地，除一般指示外，很少具體的領導。在研究所方領導骨幹缺之泛，各所所 長文多忙於行政事務，有的幾乎等於圣部脱離研究業務，工作中忙縭與上下脱炧現稚问

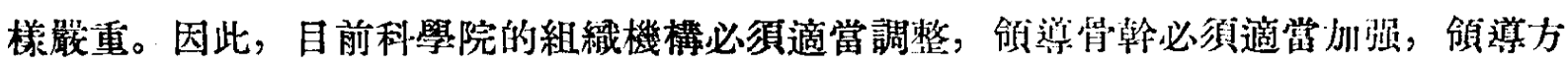
法必須徹底改變，否則就無法在現有基堡上把我國的科學事業發展起來，因而也就無法 在我國社會主義工栄化的偉大事業中完成其光策的職責。

\section{$\equiv$}

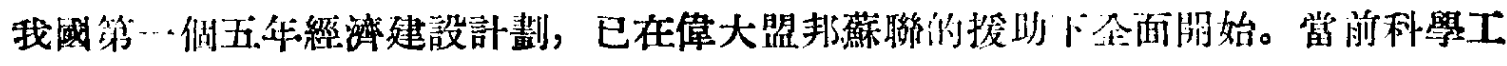




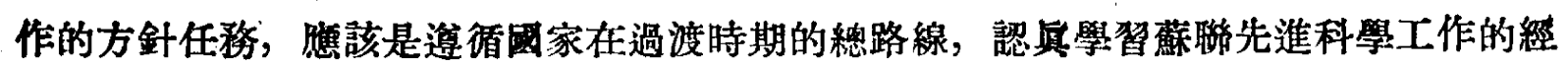
驗, 積極支援國家建設, 發揮科學家的高度皘極性和㓣造性, 在實踐中發展我郡的科學 事業，充實我郡的科學榢伍，临堅决實現國家建設的總路線和總任務而努力。沒有科學 - 技術的不斷支援和科學事業的相隹發展, 要完成國家的社會主義工業化的任務是不可能 的; 反之，離開了積極支援國家建設的科學實踐，要達到發展科學事業的目的也同焃是 不可能的。

根據以上精神，提出科學院當前的主要工作任務如下:

（一）在現有基礎上把目前可以使用的科學力量適常組織起來，全力支援國家工業 建設，首先是重工業建設。技術科學方面，各所隹以解決砤冶、煤炭、石油、機械動力 和土木建筑等方面的問題䍃主, 並與工業部門取得密切聯系, 按照現有人力、設備和業 務水平，實事求是地解決當前工業建設利國防建設中所提出的閣題。争取在聯系筫際、 總結工程技術人員和廣大工人辣衆的具體緸驗中，在科學業務水本的不斷提偪中，作出 更多更大的貢獻。

（二）有重點地對正在建設或即將建設的工業中心或經濟區域，淮行地下地上資源 和自然條件的調查研究，向有關部門提出合理利用國家資源的具體建議或參考疼料。通 不僅念國家建設所迫切需要，同時也是地學和生物科學本身的發展所必需。我國蕉有資 料貧乏，我僻必須對我國的自然、社會和歷近進行周密的調查研究，在大量佔有材料的 基礎上充實、發展與提高我國的科學事業。特別是對於農業、水產、林業以及畜牧業等 方面的發展, 都要隻行有計劃的調查研究工作。

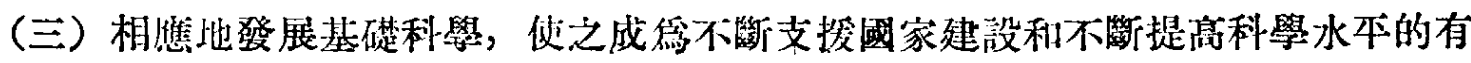

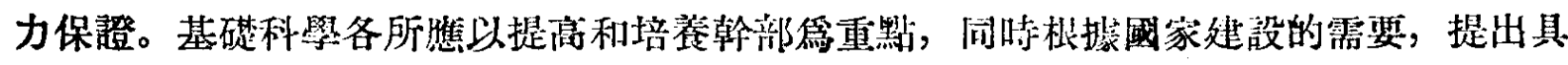
有關煡性的科學問題，並認其地加以研究，俘筆取能够綜合解決國家建設中所提出的重 大科學問題積極準借條件。計劃将物理、数學、化學、生物、地質等基礁科學力量逐步 集中北京，與有關的高等學校合作；有計劃地培養可以繼緽深造的科學人材，鸽我國科 學事業的進一步全面發展打下基䂵。

（四）關於在生產上或學琎上迫切需要，而今天依然十分薄弱或根本没有基礎的學

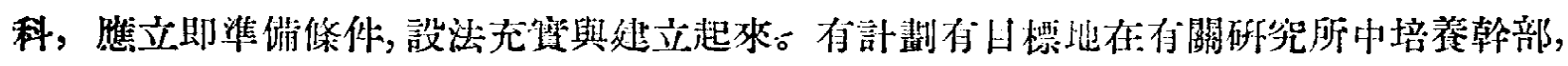

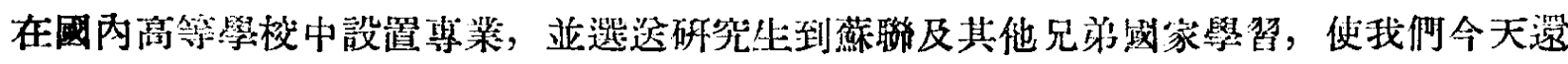

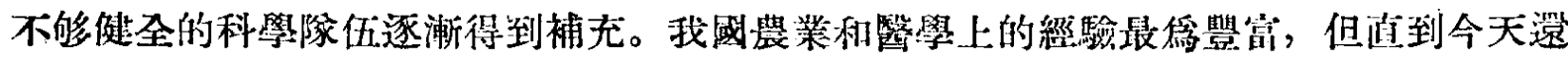

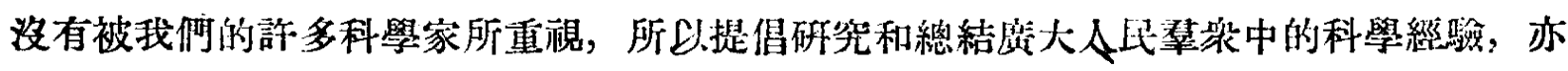
留成䍃目前發展我國科學事業的重要任務之一。

（五）設法加强让會科學方面的力量。目前社會科學方面已有經辚、語言、考古、

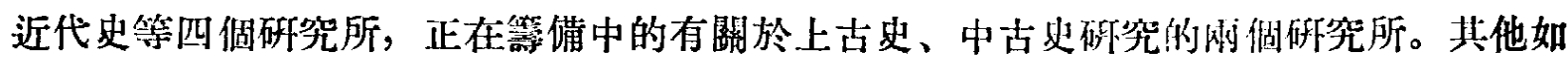

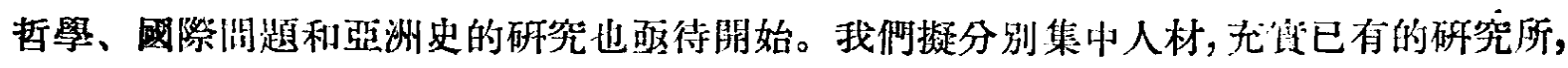

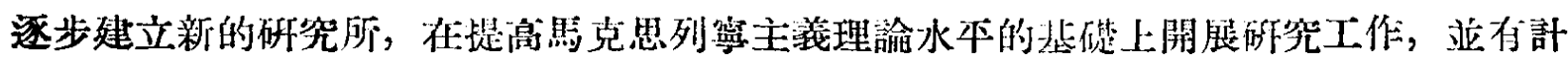

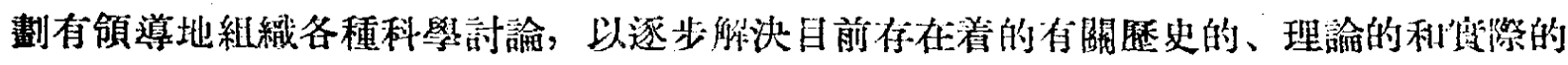
學石爭論䦓題。

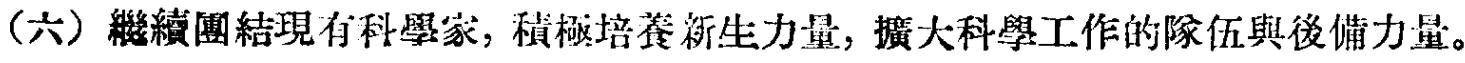




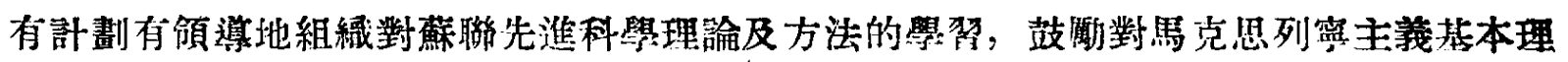

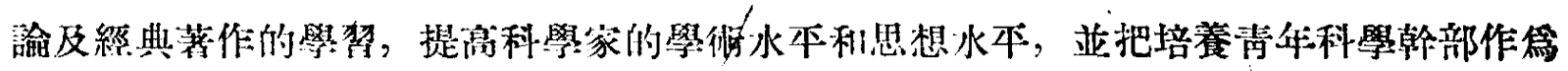
目前全部科學工作的最中心的任務。

鸽了算現上述任務, 提出如下的改進工作辦法:

（一）結合慗訂 1954 年研究計劃, 有重點地切敌整顿與改進各研究所的工作。研

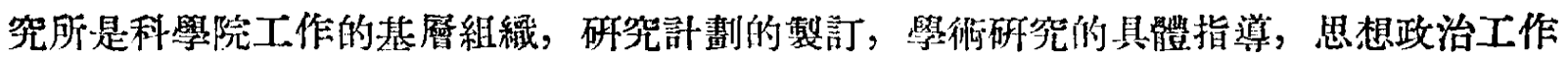
的進行, 科學幹部的提高和培養, 都非經過䂠究所不可。在慗訂各所研究計劃時, 必須

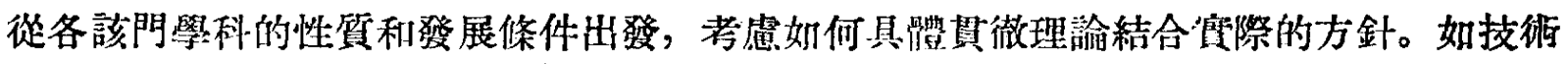
科學和部分生物科學是可以值接結合生產苗際的, 而某些基礎科學则只能間接地結合生

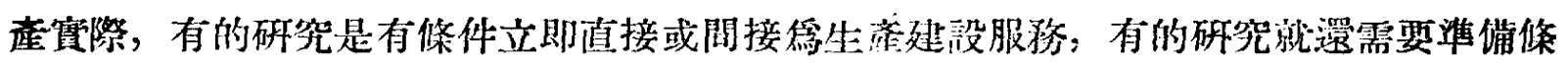
件在若干年之後才能獲得成果。必須將這些具體條作與製訂計劃们工作相結合, 經過科

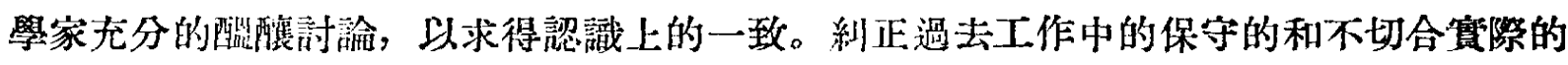
偏向，使 1954 年的研究計劃能够製訂得更加切合貝際。

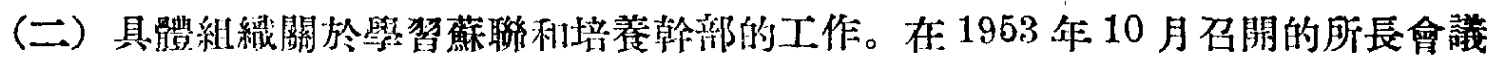

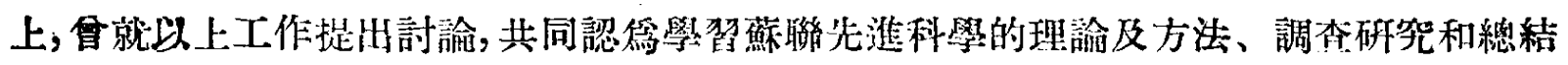
营賉經驗，是提高我國科學水本的基本環節，大力培養幹部是我國科學工作们長期的中 心任務，亚要求把這些都具體規定到工作計劃中去。過去科學院學習蘇聯较大學䍃落後， 在訪蘇代表團歸來以後，情况已有所轉變，然仍處於你計劃狀態中。今後㗹强調有計劃 的學習，不僅學習蘇聯先進科學理諭，而且要學習他們工作的方法、精种利態度。特別

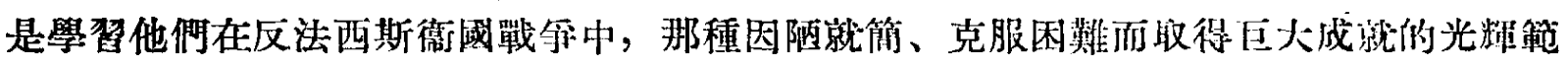
例。我㑚建議在 1954 年內邀請蕉聯科學院派一個代表團來我國考察，使蘇聯科學家在

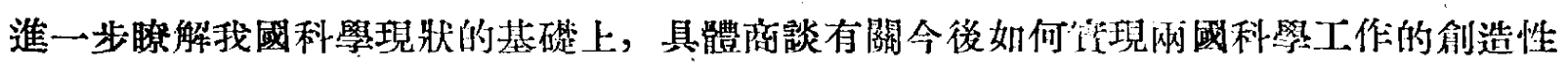
合作問題。此外, 琗固俄交學㚙, 繼續檢查各所對現有楛刊的使用情况, 有重點地組織

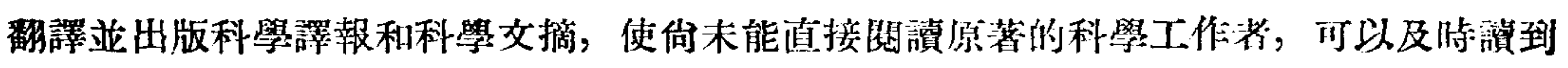

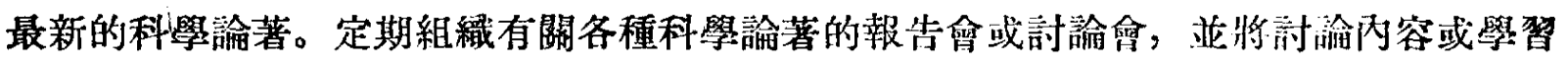
心得第成論文發表。

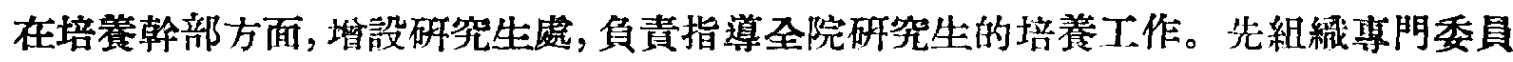
會討論並擬訂研究生條例和學術獎散辦法, 爭取在 1954 年第三季度內招收第一期研究

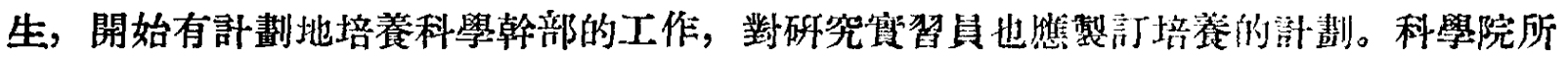
屬研究機構分佈各地，大體說隶，物理、數學、化學、地學和社會科學将筷中於北京; 士 壤、天交主要在南京; 生理、生化主要在上海; 技術科學主要在東北。由於㦄史條件及房 屋設備的限制，最近若千年内不可能有大的變動，因此希望中央高等呚育部在高等學校 中開設専業上能考慮到上述地區分佈情况，以便科學院的滈級䂰究人員能在大學策課， 大學敉師也能百便利地策做科學研究工作，集中力量共同瀂國家培養科學研究人材。

（三）爲保䙞科學工作任務的順利完成, 使科學工作有效地䍃國家建設服務, 在改 善領導機構和領導方法上擬請探取如下的措施:

1、建議在國家計劃委員會內成立專門機構, 負责綜合寀查科學政究計劃, 以便各科

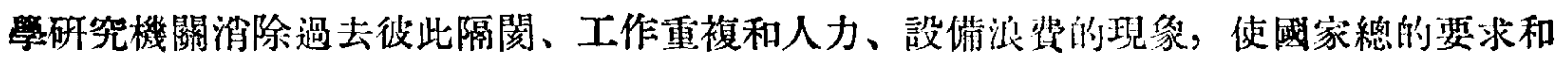


各個方面的科學研究機構的力量有機地密切聠系和配合起來。

2、科學院所屬技術科學的各研究所, 與有關工業部門和其他部門取得密切婘系, 每 行䌊常的創造性合作。各所工作任務的提出, 研究計劃的製訂, 均由科學院及各研究所 與相關的工業部共同審核，縃常業務與行政領導則仍由科學阮負責。這樣就可以把隻方 關係全面地打通, 充分發揮潛在力量, 使技術科學研究與國家工業建設相結合, 避免研 究工作脱離國家需要，或國家交下任務過多洏各研究所文無法權衡輕重的現像。

3、加强科學院的領導。在院務會議下成立秘書處，遴選科學家若干人充任秘書，成 嚕院務會議在學術領導方面的有力助手。院對各研究所分學部領導, 擬暫分䈆物理學數 學化學部、技術科學部、生物學地學部、社會科學部等四個學部; 各個學部由所屬各所 所長及院內外有關專家組織學部委員會（學部委員會組織條例另行規定）；學部委員會 只管學術領導，不管行政事務。另堆設人事局，加强對科學幹部的管理和培養工作；㘿 設編譯出版委員會，負責領導並具體規劃全院的編臎出版工作。

4、改進研究所的領導。各所設立學術委員會, 由本所所長及所內外有關尃产組成(所 的學随委員會組緎條例另行規定); 其任務召製訂研究計劃，領導學術討論會，審查科 學論交及培養研究生等。所設行政副所長, 建立行政機構, 減輕研究人員的行政負担, 加强政治思想領導。所有分散在各地的研究所、室及天交台、地震台和工作站，其日常 的政治工作、思想教育及日常工作的監督, 均由各該單位所在地的政府統一領導進行。

5、加强東北分院、華東辦事處對所在地各所的領導。並準備在西安、昆明及廣州設 立西北分院籌備處、西南綜合研究所箒備處及華南工作站, 均分別委託各大行政區代 管。 